\title{
Cutaneous Abnormalities in Chronic Kidney Disease Patients with and without Dialysis
}

\author{
Md. Obaidur Rahman ${ }^{1 *}$, Muhammad Rafiqul Alam², Asia Khanam², Md. Rezaul Alam², \\ Md. Kabir Hossain ${ }^{2}$, A. K. M. Shahidur Rahman², Fahmida Haque ${ }^{3}$ \\ ${ }^{1}$ Department of Nephrology, Cumilla Medical College \& Hospital, Cumilla, Bangladesh \\ ${ }^{2}$ Department of Nephrology, Bangabandhu Sheikh Mujib Medical University (BSMMU), Dhaka, Bangladesh \\ ${ }^{3}$ Department of Dermatology, CARe Medical College \& Hospital, Dhaka, Bangladesh \\ Email: ${ }^{\star}$ obaidurrahman757@gmail.com
}

How to cite this paper: Rahman, Md.O., Alam, M.R., Khanam, A., Alam, Md.R., Hossain, Md.K., Rahman, A.K.M.S., and Haque, F. (2020) Cutaneous Abnormalities in Chronic Kidney Disease Patients with and without Dialysis. Journal of Biosciences and Medicines, 8, 64-76.

https://doi.org/10.4236/jbm.2020.81008

Received: November 30, 2019

Accepted: January 6, 2020

Published: January 9, 2020

Copyright (c) 2020 by author(s) and Scientific Research Publishing Inc. This work is licensed under the Creative Commons Attribution International License (CC BY 4.0).

http://creativecommons.org/licenses/by/4.0/

\begin{abstract}
Background: Chronic kidney disease (CKD) is increasingly prevalent worldwide. CKD may present with different cutaneous manifestations. Objectives: To evaluate the dermatological manifestations and compare these manifestations between patients with maintenance hemodialysis (MHD) and nondialysis groups. Methods: It was a cross sectional study conducted in the Department of Nephrology, Bangabandhu Sheikh Mujib Medical University (BSMMU), Dhaka, Bangladesh from April 2013 to March 2014. A total of 150 hospital admitted CKD patients were evaluated for dermatological manifestations. Age, gender, haemoglobin level, 24-hours urinary total protein (UTP), serum creatinine, serum fasting lipid profile, estimated glomerular filtration rate (e-GFR) and dermatological manifestations of the study subjects were recorded accordingly. Inter-group comparisons were made between patients with and those without cutaneous abnormality. Results: Out of 150 study subjects, 99 (66\%) were male and 51 (34\%) were female, 69 (46\%) patients were on MHD and $81(54 \%)$ patients were without dialysis, their mean $( \pm \mathrm{SD})$ age was $44.6 \pm 12.3$ year. A Total of $126(84 \%)$ patients had cutaneous abnormalities; among them 69 (54.76\%) were pre-dialytic and 57 (45.24\%) were on MHD group. The mean $( \pm S D)$ serum creatinine was relatively higher but haemoglobin level was significantly lower $(p=0.021)$, while UTP was significantly higher $(\mathrm{p}=0.038)$ among patients with cutaneous abnormality. There was no relationship between lipid profile with cutaneous abnormality. Among 126 (84\%) patients with cutaneous abnormality; pallor was the most common cutaneous abnormality (72\%) followed by xerosis (68.66\%), pruritus $(65.33 \%)$, half and half nails (38.66\%), pigmentation (33.33\%), purpura/ecchymosis (16.66\%), fungal infection (16\%), ulcerative stomatitis (10.66\%) and bacterial infection (10\%). Pigmentation (52.6\%), purpura (35.1\%), ulcerative stomatitis
\end{abstract}


(21.1\%) and bacterial infection (19.3\%) were significantly higher in MHD group. Among 69 (54.76\%) pre-dialytic patients; 11 (15.94\%), 20 (28.98\%) and 38 (55.07\%) of them were on CKD stage-III, IV and V respectively. Conclusions: The dermatological disorders are frequent among CKD patients. Pallor, pruritus, xerosis, pigmentation and purpura are predominant changes. Pigmentation, purpura, ulcerative stomatitis and bacterial infection are significantly higher in MHD patients. Cutaneous abnormalities are more frequent in advance stages of CKD.

\section{Keywords}

Chronic Kidney Disease (CKD), Cutaneous Manifestations, Maintenance Hemodialysis (MHD)

\section{Introduction}

Chronic kidney disease (CKD) is an irreversible and progressive process, growing as a global public health problem. It affects $10 \%-16 \%$ of the adult population in Asia, Australia, Europe and the United States [1]. In Bangladesh about $18 \%-20 \%$ patients are suffering from CKD [2]. It results in end stage renal disease (ESRD) where patient has to be dependent on renal replacement therapy (dialysis/transplantation) for survival [2].

CKD has been associated with many other chronic conditions like anaemia, bone and mineral disorder, cardiovascular disease, dyslipidemia, poor nutritional status, altered cognitive function etc. [3].

The skin is the largest body organ that shows remarkable functional and structural diversity [4]. It is the most visible and accessible organ of the body, may function as an important diagnostic clue to the disease affecting internal organs including renal system [5]. It has been reported that persistent cutaneous complains such as xerosis and intractable pruritus need searching for underlying renal dysfunction [6]. Skin manifestation may be the first important sign of CKD [7]. It has been found that 50\% - 100\% patients with ESRD have at least one associated cutaneous change [8]. Some of these cutaneous disorders disappear following kidney transplantation, confirming that the metabolic changes resulting from the malfunctioning kidney is responsible for some of these changes. Other lesions may be related to the cause of CKD. It is known that dialysis prolongs the life of CKD patients thus allowing them to develop further complications including cutaneous disorders. Many of the skin problems are benign and do not affect the course of CKD, however, some of them may suggest the presence of a serious systemic disorder in these patients [8].

CKD is associated with different kinds of skin problems and ranges from the nearly universal xerosis and pruritus to uncommon conditions like purpuric skin changes, acquired perforating dermatosis and nail changes [9]. In CKD with a progressive decline of estimated glomerular filtration rate (e-GFR), the kidney 
fails to maintain a normal level of waste products of protein metabolism such as urea and creatinine. The prevalence of some of these disorders is associated with severity and duration of CKD and may precede or follow the onset of dialysis [10] [11]. Maintenance hemodialysis (MHD) might improve some of the disorders by removing the risk factors related to uremia and predispose to develop newer disorders by prolonging the life [12].

Xerosis (rough and scaly skin) was the most common (46\%-90\%) cutaneous abnormality among CKD patients observed in previous reports [13] [14]. Pruritus is one of the most characteristic and annoying cutaneous symptoms of CKD [5] [15]. Cutaneous disorders may be episodic or constant, localized or generalized and mild to severe in intensity [14]. Dermatological abnormalities can significantly affect patients' quality of life with a negative impact on their mental and physical health. Early detection and treatment of severe cutaneous disorders can dramatically alter their course with improvement the quality of life [16]. This study was done to find out the rate and pattern of dermatological disorders in CKD (Stage III-V) and dialysis-dependent chronic kidney disease patients.

\section{Materials and Methods}

This was a cross sectional study conducted in Department of Nephrology, Bangabandhu Sheikh Mujib Medical University (BSMMU), Dhaka, Bangladesh from April 2013 to March 2014. This study was approved by the Ethical Review Committee, BSMMU, Dhaka, Bangladesh. According to the statistical calculation a total of 150 hospital admitted patients with CKD (Stage III-V and on MHD) were selected purposively. Sample size was estimated by using, $n=z^{2}(p \times q) / d^{2}$ formula; where allowable error 5\% with 95\% confidence level. Assuming a 50\% prevalence of cutaneous abnormality among CKD patients [8], the required sample size was 384 . Because it was a single centre study and time constraints, a total of 150 patients were studied. Hospital admitted adult (age $>18$ year) CKD patients of stages III-V, with or without dialysis and given consent on detailed briefing about the purpose and nature of the study were consecutively recruited in this study. Patients with clinical picture or investigations suggesting acute kidney injury (AKI), kidney transplantation and with previous skin diseases were excluded.

Among total 150 CKD patients, 69 patients with maintenance hemodialysis (MHD) and 81 patients without dialysis were finally entered in this study.

Detailed general and systemic examinations were performed. Demographic, clinical and laboratory data of each patient were collected accordingly. Laboratory investigations included complete blood count (CBC), serum creatinine, Urinary Total Protein (UTP) in 24 hours and serum fasting lipid profile [Serum total cholesterol, serum triglyceride, serum low density lipoprotein cholesterol (S. LDL-C), serum high density lipoprotein cholesterol (S. HDL-C)]. Estimated glomerular filtration rate (e-GFR) of each patient was calculated by CockcoftGault (CG) formula, and according to the e-GFR, patients were assigned differ- 
ent stages of CKD using ${ }^{\star}$ KDIGO, 2012 guideline. Scraping for fungus and potassium hydroxide mount were done wherever clinically indicated. Skin manifestations of the study subjects were evaluated by a qualified skin specialist in the Department of Dermatology, BSMMU, Dhaka, Bangladesh.

The participants were divided into two groups based on the presence or absence of cutaneous abnormality. The outcome variables analyzed between the two groups were age, gender, haemoglobin level, serum creatinine, UTP in 24 hours and serum fasting lipid profile. All necessary and relevant data of the patients were recorded in a pre-tested data sheet.

\subsection{Common Cutaneous Changes Associated With CKD}

Pruritus: Itchy skin also known as pruritus is an unpleasant and irritating sensation that increases the desire to scratch, which can be caused or worsened by dry skin.

Xerosis (rough and scaly skin): Abnormal dryness of the skin and mucous membranes caused by a lack of moisture in the skin.

Pallor: Pallor is a pale color of the skin that can be caused by anemia and is the result of a reduced amount of haemoglobin.

Hyperpigmentation/pigmentation: Hyperpigmentation is the darkening of an area of skin or nails caused by increased melanin.

Purpura/Ecchymosis: Purpura/ecchymosis is a condition of red or purple discolored spots on the skin. The spots are caused by bleeding underneath the skin.

Ulcerative stomatitis: Refers to the erosions and ulcerations in the mouth. Lesions are located on the buccal mucosa (inside of the cheeks) or on the gingiva (gums).

Bacterial infection: Bacterial infection is a common infection of the skin and the soft tissues underneath such as cellulitis, impetigo, erysipelas, folliculitis, furuncles, carbuncles etc. It happens when bacteria enter through a break skin and spread.

Fungal infection: Fungal infections of the skin are very common and include athlete's foot, jock itch, ringworm and yeast infections.

Half and half nails: Half and half nails (also known as "Lindsay's nails") show the proximal portion of the nail white and the distal half red, pink or brown, with a sharp line of demarcation between the two halves.

\subsection{Definition of CKD}

According to ${ }^{\star} \mathrm{KDIGO} 2012$ Clinical Practice Guideline for the Evaluation and Management of Chronic Kidney Disease, CKD is defined as abnormalities of kidney structure or function, present for $>3$ months.

\subsection{Stages of CKD}

${ }^{\star} \mathrm{KDIGO}$ suggested the following stages of CKD: 
- Stage I: normal e-GFR $\geq 90 \mathrm{~mL} / \mathrm{min}$ per $1.73 \mathrm{~m}^{2}$.

- Stage II: e-GFR between 60 to $89 \mathrm{~mL} / \mathrm{min}$ per $1.73 \mathrm{~m}^{2}$ (mildly decreased renal function).

- Stage IIIa: e-GFR between 45 to $59 \mathrm{~mL} / \mathrm{min}$ per $1.73 \mathrm{~m}^{2}$ (Mild to moderately decreased renal function).

- Stage IIIb: e-GFR between 30 to $44 \mathrm{~mL} / \mathrm{min}$ per $1.73 \mathrm{~m}^{2}$ (Moderate to severely decreased renal function).

- Stage IV: e-GFR between 15 to $29 \mathrm{~mL} / \mathrm{min}$ per $1.73 \mathrm{~m}^{2}$ (Severely decreased renal function).

- Stage V: e-GFR of $<15 \mathrm{~mL} / \mathrm{min}$ per $1.73 \mathrm{~m}^{2}$ (Kidney failure).

$\left[{ }^{\star} \mathrm{KDIGO}=\right.$ Kidney Disease Improving Global Outcomes $]$.

\subsection{Statistical Analysis of Data}

Data cleaning validation and analysis was performed using the Statistical Package for Social Science (SPSS) software for Windows version-14. Categorical data was presented as frequency, percentage and continuous variable was expressed as mean \pm SD (standard deviation). Unpaired Student's " $t$ " test and Chi-square test (with fisher exact modification) were performed to calculate the statistical differences and/or association between groups where applicable. $\mathrm{p}$ value $<0.05$ was taken as level of significance.

\section{Results}

To evaluate the dermatological manifestations and compare these manifestations between patients with maintenance hemodialysis (MHD) and non-dialysis groups we had evaluated 150 hospital admitted CKD patients. Of them 69 (46\%) patients were on MHD and 81 (54\%) patients were without dialysis. Based on the presence or absence of cutaneous abnormality, total study subjects were divided into two groups: Group-A (cutaneous abnormality present) and Group-B (cutaneous abnormality absent). Among the total 150 study subjects, 126 (84\%) patients had cutaneous abnormalities and $24(16 \%)$ patients had no cutaneous abnormality (Table 1).

Out of 150 study subjects 99 (66\%) were male and 51 (34\%) were female (Table 2). Of them, 85 (67.5\%) male and 41 (32.5\%) female had cutaneous abnormality, but the difference was not statistically significant $(\mathrm{p}=0.387)$ (Table 2$)$.

Table 1. Status of cutaneous abnormality in the study patients with ${ }^{\star} \mathrm{CKD}$.

\begin{tabular}{ccc}
\hline & Frequency & Percentage $\%$ \\
\hline Total study patients & 150 & \\
Cutaneous abnormality present (G-A) & 126 & $84 \%$ \\
Cutaneous abnormality absent (G-B) & 24 & $16 \%$ \\
On maintenance hemodialysis ${ }^{* *}$ MHD) & 69 & $46 \%$ \\
Without dialysis & 81 & $54 \%$ \\
\hline
\end{tabular}

${ }^{\star} \mathrm{CKD}=$ Chronic Kidney Disease $;{ }^{*} \mathrm{MHD}=$ Maintenance Hemodialysis. 
Mean $( \pm \mathrm{SD})$ age (year) of the total study subjects was $44.6 \pm 12.3$. In Group-A mean $( \pm S D)$ age of the participants was $46.1 \pm 14.3$ year, in Group-B mean $( \pm S D)$ age of the participants was $42.3 \pm 11.0$ year and mean age difference between the two group was not significant $(\mathrm{p}=0.220)$ (Table 2$)$.

The mean $( \pm \mathrm{SD})$ haemoglobin level $(\mathrm{gm} / \mathrm{dl})$ of patients with cutaneous abnormality (Group-A) was $7.82 \pm 1.42 \mathrm{~g} / \mathrm{dl}$ and patients without cutaneous abnormality (Group-B) was $8.57 \pm 1.59 \mathrm{~g} / \mathrm{dl}$. The observed difference of mean haemoglobin level between the group was statistically significant $(p=0.021)$ (Table 3).

The mean $( \pm \mathrm{SD})$ serum creatinine $(\mathrm{mg} / \mathrm{dl})$ was relatively higher in Group A patients than Group B patients that was $7.56 \pm 3.63 \mathrm{mg} / \mathrm{dl}$ and $6.66 \pm 3.22 \mathrm{mg} / \mathrm{dl} \mathrm{re}-$ spectively, but the difference was not statistically significant $(\mathrm{p}=0.260)$ (Table 3$)$.

The mean $( \pm \mathrm{SD})$ UTP $(\mathrm{gm} /$ day) of patients in Group-A was $2.02 \pm 1.03$ $\mathrm{gm} /$ day and that was $1.53 \pm 1.08 \mathrm{gm} /$ day in Group-B. Therefore proteinuria between the two groups showed a significant difference $(p=0.038)$ (Table 3$)$.

The mean $( \pm \mathrm{SD})$ lipid profile of patients in Group-A and in Group-B were Table 2. Gender and age of the study patients.

\begin{tabular}{ccccc}
\hline Parameters & Total & Group A & Group B & *p Value \\
\hline $\begin{array}{c}\text { Study subjects } \\
\text { Gender }\end{array}$ & $\mathrm{n}=150$ & $\mathrm{n}=1126$ & $\mathrm{n}=24$ & \\
Male n (\%) & $99(66 \%)$ & $85(67.5 \%)$ & $14(58.3 \%)$ & 0.387 \\
Female n (\%) & $51(34 \%)$ & $41(32.5 \%)$ & $10(41.7 \%)$ & \\
Age (yrs) & $44.6 \pm 12.3$ & $46.1 \pm 14.3$ & $42.3 \pm 11.0$ & \\
Mean \pm SD & $18.0-70.0$ & $18.0-70.0$ & $20.0-57.0$ & \\
Range & & & & \\
\hline
\end{tabular}

Values in the parenthesis denote corresponding percentage; ${ }^{\star} \mathrm{P}<0.05$ was taken as level of significance; Unpaired Student's " $t$ ” test/Chi-square test was performed.

Table 3. Laboratory investigations of the study subjects.

\begin{tabular}{cccc}
\hline Laboratory Parameters & Group A & Group B & * p Value \\
Remoglobin $(\mathrm{gm} / \mathrm{dl})$ & $7.82 \pm 1.42$ & $8.57 \pm 1.59$ & $\mathbf{0 . 0 2 1}$ \\
Range & $4.00-14.40$ & $5.40-11.70$ & \\
Serum creatinine $(\mathrm{mg} / \mathrm{dl})$ & $7.56 \pm 3.63$ & $6.66 \pm 3.22$ & 0.260 \\
Range & $1.90-22.10$ & $1.90-13.20$ & \\
UTP $($ gm/day) & $2.02 \pm 1.03$ & $1.53 \pm 1.08$ & 0.038 \\
S. Total Cholesterol $(\mathrm{mg} / \mathrm{dl})$ & $195.5 \pm 33.0$ & $189.8 \pm 33.01$ & 0.442 \\
S. Triglyceride $(\mathrm{mg} / \mathrm{dl})$ & $197.8 \pm 65.6$ & $186.6 \pm 57.5$ & 0.395 \\
S. LDL-C $(\mathrm{mg} / \mathrm{dl})$ & $121.1 \pm 29.8$ & $115.2 \pm 30.5$ & 0.378 \\
S. HDL-C $(\mathrm{mg} / \mathrm{dl})$ & $34.6 \pm 9.9$ & $38.0 \pm 8.3$ & 0.119
\end{tabular}

${ }^{\star} \mathrm{P}<0.05$ was taken as level of significance. Unpaired Student's “t” test/Chi-square test was performed. 
evaluated. Serum total cholesterol, serum triglyceride, serum low density lipoprotein cholesterol (S. LDL-C), serum high density lipoprotein cholesterol (S. HDL-C) were $195.5 \pm 33.0,197.8 \pm 65.6,121.1 \pm 29.8,34.6 \pm 9.9 \mathrm{mg} / \mathrm{dl}$ and $189.8 \pm 33.01,186.6 \pm 57.5,115.2 \pm 30.5,38.0 \pm 8.3 \mathrm{mg} / \mathrm{dl}$ in Group A and in Group B respectively. The observed values between two groups did not show any statistically significant difference ( $\mathrm{p}$ value $0.442,0.395,0.378$ and 0.119 respectively) (Table 3).

In this study, it was observed that, the most prevalent skin manifestation was pallor, which was seen in 108 patients (72\%). Other skin manifestations include xerosis $103(68.66 \%)$, pruritus 98 (65.33\%), Half and half nails 58 (38.66\%), pigmentation 50 (33.33\%), purpura/ecchymosis 25 (16.66\%), fungal infection 24 (16\%), ulcerative stomatitis 16 (10.66\%) and bacterial infection 15 (10\%) (Table 4).

Out of a total of 150 study population, 69 (46\%) patients were on MHD and 81 (54\%) patients were without dialysis. Among the 69 patients with dialysis, 57 $(82.60 \%)$ patients had cutaneous manifestations and among 81 patients without dialysis, 69 (85.18\%) patients showed cutaneous manifestations. It has been observed that CKD patients with dialysis had significantly [ $(\mathrm{p}=0.007),(\mathrm{p}=0.0001)$, $(\mathrm{p}=0.015)$ and $(\mathrm{p}=0.027)]$ higher incidence of pigmentation $30(52.6 \%)$, purpura $20(35.1 \%)$, ulcerative stomatitis $12(21.1 \%)$ and bacterial infection $11(19.3)$ than CKD patients without dialysis 20 (29.0\%), 5 (7.2\%), 4 (5.8\%) and 4 (5.8\%) respectively. Other cutaneous manifestations between the study groups did not show any significant difference (Table 5).

Out of 150 study subjects, 126 (84\%) patients had cutaneous abnormality. Of them, 69 (54.76\%) patients were in pre-dialytic stages (CKD III-V, without dialysis) and 57 (45.24\%) patients were on MHD. Among the pre-dialytic 69 (54.76\%) patients; 11 (15.94\%) patients were in CKD stage-III, 20 (28.98\%) patients were in CKD stage-IV and 38 (55.07\%) patients were in CKD stage-V. Therefore, it has been observed that cutaneous abnormalities were more frequent in advance stages of CKD (Table 6).

Table 4. Types of cutaneous abnormalities present in the study subjects $(\mathrm{n}=150)$.

\begin{tabular}{ccc}
\hline Types of Cutaneous Abnormality & Frequency (n) & Percentage (\%) among Total Patients \\
\hline Pallor & 108 & $72 \%$ \\
Xerosis & 103 & $68.66 \%$ \\
Pruritus & 98 & $65.33 \%$ \\
Pigmentation & 50 & $33.33 \%$ \\
Purpura/Ecchymosis & 25 & $16.66 \%$ \\
Ulcerative stomatitis & 16 & $10.66 \%$ \\
Bacterial infection & 15 & $10 \%$ \\
Fungal infection & 24 & $16 \%$ \\
Half-and-half nail & 58 & $38.66 \%$ \\
\hline
\end{tabular}

*Some participants have more than one finding. 
Table 5. Comparison of cutaneous abnormalities in CKD patients on dialysis (MHD) and without dialysis (Stage-III, IV, V).

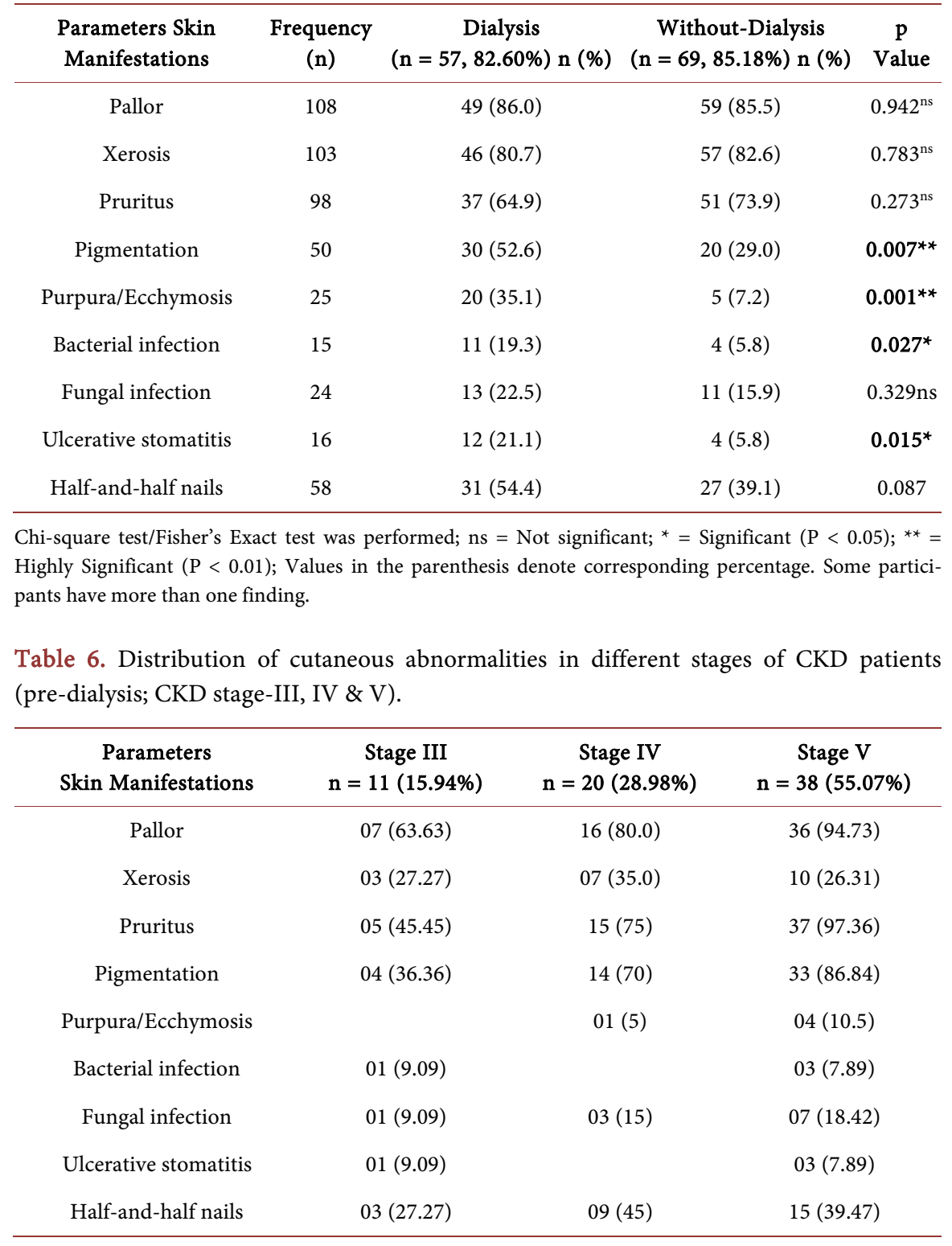

Values in the parenthesis denote corresponding percentage. Some participants have more than one finding.

\section{Discussion}

Cutaneous manifestations are very common in patients with chronic kidney disease (CKD). We have evaluated 150 hospital-admitted CKD patients for dermatological manifestations and compare these manifestations between patients with maintenance hemodialysis (MHD) and pre-dialysis groups. Based on the presence or absence of cutaneous abnormality, total study subjects were divided into two groups: Group-A (cutaneous abnormality present) and Group-B (cutaneous abnormality absent). Of them, 69 (46\%) patients were on MHD and 81 (54\%) patients were without dialysis. Among the 69 patients with dialysis 57 (82.60\%) had cutaneous manifestation and among 81 patients without dialysis 
69 (85.18\%) showed cutaneous manifestation.

Among the total 150 study subjects, 126 (84\%) patients had cutaneous abnormalities and 24 (16\%) patients had no cutaneous abnormality. Udayakumar et al. have performed a study among CKD patients receiving haemodialysis and found cutaneous disorders were in $82 \%$ study participants [7]. In our study population, $84 \%$ of CKD patients had some form of cutaneous disorder and $82.60 \%$ of CKD patient on MHD had cutaneous manifestation. These findings accorded with previous study as reported that, $96 \%$ of patients with different stages of CKD had at least one dermatological manifestation [7] [10].

In this study, 99 (66\%) patients were male and 51 (34\%) patients were female. Among the male patients, $65.5 \%$ (85) and among the female $32.5 \%$ (41) showed cutaneous abnormalities. There was no statistically significant difference ( $\mathrm{p}=$ 0.387 ) between male and female CKD patients in development of cutaneous abnormalities.

It was observed that low haemoglobin level $(\mathrm{p}=0.021)$ and high proteinuria $(\mathrm{p}=0.038)$ were associated with development of cutaneous abnormality. Serum creatinine was relatively higher among patients with cutaneous abnormality however, this difference was not statistically significant $(p=0.260)$. Serum fasting lipid levels had no association with development of cutaneous abnormalities.

Among the cutaneous abnormalities, Pallor of the skin was most common. Thomas et al. [17] observed pallor in 45.45\%, but Shah et al. [18] observed pallor in as high as $91.5 \%$ study population. It was observed in $72 \%$ and was the most common skin manifestation among CKD patients in this study. Pallor is due to anemia. In this study mean $( \pm S D)$ haemoglobin level in cutaneous abnormality positive group was $7.82 \pm 1.42 \mathrm{~g} / \mathrm{dl}$, and cutaneous abnormality negative group was $8.57 \pm 1.59 \mathrm{~g} / \mathrm{dl}$, p value was 0.021 which was significant. Anemia in CKD results from decreased erythropoeisis, reduced red cell life span and blood loss during dialysis [19]. In present study, 85.5\% CKD patients without MHD and $86 \%$ with MHD were pallor. Thus pallor was found slight increased in frequency in dialysis patients though statistically it was not significant $(\mathrm{p}=0.942)$. Similar study conducted by Shah et al. [18] and found 94.3\% CKD patients without MHD and $89.6 \%$ CKD patients with MHD were pallor. Thomas et al. [17] also found pallor more common in CKD patients on MHD. Pallor was found more in $\mathrm{CKD}$ patients with MHD group, probably due to more blood loss during dialysis in this group.

Xerosis (rough and scaly skin) was a leading skin disorder reported in $46 \%$ 90\% CKD patients [13] [14] [20]. Xerosis was the most common cutaneous abnormality $(79 \%)$ in the study done by Udayakumar et al. among patients on dialysis [7]. Thomas et al. [17] and Leena et al. [21] also observed xerosis $66.7 \%$ and $61 \%$ respectively. It has been observed in $68.66 \%$ and was the second most common skin manifestation among CKD patients in this study, which accorded with previous findings. Shah et al. [18] found $80 \%$ CKD patients without MHD and $72.9 \%$ CKD patients with MHD had xerosis. In the present study, we also 
found $82.6 \%$ CKD patients without MHD and $80.7 \%$ CKD patients with MHD had xerosis. A reduction in the size and functional abnormality of eccrine sweat glands, suggesting compromised eccrine secretion leading to epithelial dehydration may contribute to the development of xerosis [22]. The tropical climate with greater sun exposure and resultant chronic dehydration may also the contributory factor to develop xerosis [23].

Pruritus is a frequent skin symptom of CKD patients. There is wide variation $(15 \%-90 \%)$ in its prevalence reported by various workers [23]. Udayakumar et al. [7] and Leena et al. [23] found the prevalence of pruritus among CKD patients was 53\%. In this study, $65.3 \%$ of CKD patients complained of pruritus and this finding was similar to previous studies. Shah et al. [18] found pruritus was present in $57.1 \%$ and $62.5 \%$ among CKD patients without MHD and CKD patients with MHD respectively, in present study we also found pruritus in 73.9\% CKD patients without MHD and 64.9\% CKD patients with MHD respectively. The cause of pruritus in CKD patients is multifactorial and may or may not improve with dialysis [11].

Diffuse hyperpigmentation has been reported in $36.7 \%$ and $37 \%$ CKD patients by Thomas et al. [17] and by Leena et al. [21] respectively. Diffuse hyperpigmentation on sun-exposed areas were seen in $33.3 \%$ among total CKD patients in this study, which was consistent with these previous studies. Diffuse hyperpigmentation has been reported in 36.7\% CKD patients with MHD [24]. In this study hyperpigmentation was found in 20 (29\%) CKD patients without MHD and 30 (52.6\%) CKD patients on MHD, which was significantly higher in dialysis group $(\mathrm{p}=0.007)$. Such pigmentation is more marked in sun exposed parts of the body of the study population, could be due to tropical climate and excessive sun exposure in these patients [10]. The incidence is higher with longer duration of dialysis and attributed to the deposition of melanin in the basal layer and superficial dermis due to failure of kidney to excrete $\beta$ melanocytic hormone that is poorly dialyzable [25].

Purpura and ecchymosis were spontaneous cutaneous bleeding affecting 9\% $20 \%$ of CKD patients [7] [24]. Thomas et al [17] found purpura in 10 (10.1\%) CKD patients, of them 7 patients were on MHD. In this study, it was seen in 25 (16.6\%) CKD patients, among whom 20 (35.1\%) were on maintenance hemodialysis and 5 (7.2\%) were without MHD, which were significantly higher in dialysis group $(p=0.001)$. Thus finding of this study was consistent with the previous reports.

In this study, ulcerative stomatitis was seen in 16 (10.66\%) CKD patients which was significantly higher (12 patients) in dialysis group $(\mathrm{p}=0.015)$. Udayakumar et al. reported that ulcerative stomatitis was $29 \%$ in dialysis group [7]. This could be attributed to the patients with poor oral hygiene in high blood urea [26]. Oral mucosal changes are predisposed by bad oral hygiene and superimposed bacterial infection in CKD patients; therefore awareness of maintaining good oral hygiene among CKD patients must be encouraged. 
Udayakumar et al. [7] found sixty-seven skin infections (13 bacterial, 42 fungal and 12 viral), distributed amongst 40 patients. Bencini et al. [27] have reported the incidence of fungal infection in patients undergoing hemodialysis to be $67 \%$. In this present study bacterial infection and fungal infection were found in $15(10 \%)$ and $24(16 \%)$ study patients respectively. Bacterial infections seen in 15 CKD patients, more marked in dialysis group 11 (19.3\%) than without dialysis group $4(5.8 \%)$, which was significant $(\mathrm{p}=0.027)$. However among total 24 study populations having fungal infection; there was no significant $(\mathrm{p}=0.329)$ difference between the dialysis and without dialysis group, which were 13 (22.5\%) and 11 (15.9\%) respectively. Therefore these observations accorded with that found in previous studies.

Previous studies have found a prevalence of half and half nails were $16 \%$ to 50.6\% [5] [7] [13]. Although half and half nails are not always seen in renal failure, they occur in as many as $40 \%$ of the patients on dialysis. Pico et al. [5] reported that the nail changes increased in prevalence with respect to time of dialysis and was significantly common in patients receiving haemodialysis. Half and half nails were found in 58 (38.66\%) CKD patients of this study and more frequent in haemodialysis patients [31 (54.4\%)] than without dialysis patients [27 (39.1\%)]. This finding was consistent with previous studies.

In this study, out of 150 study subjects, 126 (84\%) patients had cutaneous abnormalities. Of them, $69(54.76 \%)$ patients were in pre-dialytic stages (CKD III-V, without dialysis) and 57 (45.23\%) patients were on MHD. Among the pre-dialytic 69 (54.76\%) patients; 11 (15.94\%) patients were in CKD stage-III, 20 (28.98\%) patients were in CKD stage-IV and 38 (55.07\%) patients were in CKD stage-V. Therefore it has been observed that cutaneous abnormalities were more frequent in advance stages of CKD. These findings were consistent with previous study as reported that dermatological manifestations increase with increasing duration and severity of renal disease [10].

\section{Conclusion}

The dermatological disorders were frequent among CKD patients without and with dialysis. Pallor, pruritus, xerosis, pigmentation and purpura were predominant changes. Pigmentation, purpura, ulcerative stomatitis and bacterial infection were significantly higher in MHD patients. Cutaneous abnormalities were more frequent in advance stages of CKD.

\section{Limitations of Study}

It was a single centre study with a relatively small sample size.

\section{Recommendations}

To identify the correct incidence of dermatological manifestations among chronic kidney disease (CKD) patients in adult population, a large scale and multi-center study will be needed. Early recognition and management of these 
dermatological manifestations may reduce the morbidity and improve the cutaneous outcome in these patients.

\section{Conflicts of Interest}

The authors declare no conflicts of interest regarding the publication of this paper.

\section{References}

[1] Chronic Kidney Disease Prognosis Consortium, Matsushita, K., van der Velde, M., Astor, B.C., Woodward, M., Levey, A.S., de Jong, P.E., Coresh, J. and Gansevoort, R.T. (2010) Association of Estimated Glomerular Filtration Rate and Albuminuria with All-Cause and Cardiovascular Mortality in General Population Cohorts: A Collaborative Meta-Analysis. The Lancet, 375, 2073-2081.

[2] Rashid, H.U. (2004) Health Delivery System for Renal Disease Care in Bangladesh. Saudi Journal of Kidney Diseases and Transplantation, 15, 185-189.

[3] Go, A.S., Chertow, G.M., Fan, D., McCulloch, C.E. and Hsu, C.Y. (2004) Chronic Kidney Disease and the Risks of Death, Cardiovascular Events, and Hospitalization. New England Journal of Medicine, 351, 1296-1305. https://doi.org/10.1056/NEJMoa041031

[4] Garg, A., Levin, N.A. and Bernhard, J.D. (2008) Structure of Skin Lesions and Fundamentals of Clinical Diagnosis. In: Wolff, K., Golsmith, L.A., Katz, S.I., Gilchrest, B.A., Paller, A.S. and Leffell, D.J., Eds., Fitzpatrick's Dermatology in General Medicine, 7th Edition, McGraw-Hill, New York, 23-40.

[5] Picó, M.R., Lugo-Somolinos, A.Í., Sánchez, J.L. and Burgos-Caldfrón, R.A. (1992) Cutaneous Alterations in Patients with Chronic Renal Failure. International Journal of Dermatology, 31, 860-863. https://doi.org/10.1111/j.1365-4362.1992.tb03543.x

[6] Nucete, M.R. (1998) Conceptos actuales sobre la fisiopatología clínica y alteraciones bioquímicas del síndrome urémico: Una revisión. Medula, 7, 35-41.

[7] Udayakumar, P., Balasubramanian, S., Ramalingam, K.S., Lakshmi, C., Srinivas, C.R. and Mathew, A.C. (2006) Cutaneous Manifestations in Patients with Chronic Renal Failure on Hemodialysis. Indian Journal of Dermatology, Venereology, and Leprology, 72, 119. https://doi.org/10.4103/0378-6323.25636

[8] Nunley, J.R. (2002) Dermatologic Manifestations of Renal Disease. eMedicine, 550.

[9] Gilchrest, B., Rowe, J.W. and Mihm, M.C. (1975) Bullous Dermatosis of Hemodialysis. Annals of Internal Medicine, 83, 480-483. https://doi.org/10.7326/0003-4819-83-4-480

[10] Khanna, D., Singal, A. and Kalra, O.P. (2010) Comparison of Cutaneous Manifestations in Chronic Kidney Disease with or without Dialysis. Postgraduate Medical Journal, 86, 641-647. https://doi.org/10.1136/pgmj.2009.095745

[11] Sanai, M., Aman, S., Nadeem, M. and Kazmi, A.H. (2016) Dermatologic Manifestations in Patients of Renal Disease on Hemodialysis. Journal of Pakistan Association of Dermatology, 20, 163-168.

[12] Patel, T.S., Freedman, B.I. and Yosipovitch, G. (2007) An Update on Pruritus Associated with CKD. American Journal of Kidney Diseases, 50, 11-20. https://doi.org/10.1053/j.ajkd.2007.03.010

[13] Morton, C.A., Lafferty, M., Hau, C., Henderson, I., Jones, M. and Lowe, J.G. (1996) Pruritus and Skin Hydration during Dialysis. Nephrology Dialysis Transplantation, 
11, 2031-2036. https://doi.org/10.1093/oxfordjournals.ndt.a027092

[14] Siddappa, K., Nair, B.K., Ravindra, K. and Siddesh, E.R. (2000) Skin in Systemic Disease. In: IADVL Textbook and Atlas of Dermatology, 2nd Edition, Bhalani Publishing House, Mumbai, 938-984.

[15] Gupta, A.K., Gupta, M.A., Cardella, C.J. and Haberman, H.F. (1986) Cutaneous Associations of Chronic Renal Failure and Dialysis. International Journal of Dermatology, 25, 498-504. https://doi.org/10.1111/j.1365-4362.1986.tb00858.x

[16] Zucker, I., Yosipovitch, G., David, M., Gafter, U. and Boner, G. (2003) Prevalence and Characterization of Uremic Pruritus in Patients Undergoing Hemodialysis: Uremic Pruritus Is Still a Major Problem for Patients with End-Stage Renal Disease. Journal of the American Academy of Dermatology, 49, 842-846. https://doi.org/10.1016/S0190-9622(03)02478-2

[17] Thomas, E.A., Pawar, B. and Thomas, A. (2012) A Prospective Study of Cutaneous Abnormalities in Patients with Chronic Kidney Disease. Indian Journal of Nephrology, 22, 116. https://doi.org/10.4103/0971-4065.97127

[18] Shah, A., Hada, R. and Kayastha, B.M. (2013) Dermatological Disorders in Chronic Kidney Disease with and without Maintenance Hemodialysis. Journal of Nepal Medical Association, 52, 365-371. https://doi.org/10.31729/jnma.543

[19] Amatya, B., Agrawal, S., Dhali, T., Sharma, S. and Pandey, S.S. (2008) Pattern of Skin and Nail Changes in Chronic Renal Failure in Nepal: A Hospital-Based Study. The Journal of Dermatology, 35, 140-145. https://doi.org/10.1111/j.1346-8138.2008.00433.x

[20] Tawade, Y.V. and Gokhale, B.B. (1996) Dermatological Manifestations of Chronic Renal Failure. Indian Journal of Dermatology, Venereology and Leprology, 62, 155-156.

[21] Leena, J.A., Islam, M.M., Ahmed, A.S., Ahmed, D.S. and Rahman, M.M. (2012) Cutaneous Manifestations of Chronic Kidney Disease-An Observational Study in 100 Cases. Faridpur Medical College Journal, 7, 33-36. https://doi.org/10.3329/fmcj.v7i1.10296

[22] Park, T.H., Park, C.H., Ha, S.K., Lee, S.H., Song, K.S., Lee, H.Y. and Han, D.S. (1995) Dry Skin (Xerosis) in Patients Undergoing Maintenance Haemodialysis: The Role of Decreased Sweating of the Eccrine Sweat Gland. Nephrology Dialysis Transplantation, 10, 2269-2273. https://doi.org/10.1093/ndt/10.12.2269

[23] Wikström, B. (2007) Itchy Skin-A Clinical Problem for Haemodialysis Patients. Nephrology Dialysis Transplantation, 22, V3-V7. https://doi.org/10.1093/ndt/gfm292

[24] Singh, G., Verma, A.K., Singh, G. and Singh, S.J. (1992) Cutaneous Changes in Chronic Renal Failure. Indian Journal of Dermatology, Venereology, and Leprology, 58, 320.

[25] Smith, A.G., Shuster, S., Thody, A.J., Alvarez-Ude, F. and Kerr, D.N. (1976) Role of the Kidney in Regulating Plasma Immunoreactive Beta-Melanocyte-Stimulating Hormone. British Medical Journal, 1, 874-876. https://doi.org/10.1136/bmj.1.6014.874

[26] Cohen, G.S. (1997) Renal Disease, Burket's Oral Medicine Diagnosis and Treatment. 9th Edition, Lippincott-Raven, Philadelphia, 487-509.

[27] Bencini, P.L., Montagnino, G., Citterio, A., Graziani, G., Crosti, C. and Ponticelli, C. (1985) Cutaneous Abnormalities in Uremic Patients. Nephron, 40, 316-321. https://doi.org/10.1159/000183485 